this topic is poorly researched." The satisfaction of patients is one outcome that should be taken into account when different methods of providing out of hours care are being planned and evaluated. It is therefore important that sound measures of satisfaction are used.

The five studies cited by Hurwitz produced conflicting results and are difficult to interpret because of the different methods used. In four of the studies interviews were used to collect the views of patients ${ }^{2.5}$; in the fifth study a postal questionnaire was used. ${ }^{6}$ The interval between the patient receiving a visit and information about satisfaction being sought varied: the questionnaire was posted within three working days of the visit in one study and up to five years after in another. In only one study were patients who received a visit from a deputising service included. ${ }^{\circ}$ Patients were asked for their opinions about different aspects of care in the studies: the length of the wait for the doctor to visit in one, their preference for their own doctor or a deputising service in another, and both overall satisfaction and satisfaction with specific aspects of care in others. The reliability or validity of the measures used was not usually reported.

Future studies of patients' satisfaction with the provision of out of hours care should seek opinions about all relevant aspects, including overall satisfaction. Studies should be clearly concerned either with a specific event such as a recent home visit or with views about the organisation of services. The possibility that satisfaction could change because of experiences after a home visit should be acknowledged, and researchers should attempt to assess the reliability and validity of the instruments they use. Unless patients' satisfaction is measured with valid and reliable instruments we will never discover with certainty whether out of hours care is organised to meet patients' needs.

RICHARD BAKER Director, Eli Lilly National Clinical Audit Centre ROBERT MCKINLEY Senior lecturer

Department of General Practice,

University of Leicester,

Leicester General Hospital,

Leicester General HES

1 Hurwitz B. Out of hours. BMf 1994;309:1593-4. (17 December.)

Sawyer $\mathrm{L}$, Arber A. Changes in home visiting and night and
(n) weekend cover: the patient's view. $B M \mp$ 1982;284:1531-4.

3 Bollam MJ, McCarthy M, Modell M. Patients' assessment of out of hours care in general practice. $B M \mathcal{F} 1988 ; 296: 829-32$.

Cartwright A, Anderson R. General practice revisited. London Tavistock, 1981

5 Allen D, Leavey R, Marks B. Survey of patients' satisfaction with access to general practitioners. $\mathcal{F} R$ Coll Gen Pract $1988 ; 38$ 163-5.

6 Dixon RA, Williams BT. Patient satisfaction with general practitioner deputising services. $B M \mathcal{F}$ 1988;297:1519-22.

\section{Stress in NHS consultants}

EDITOR,-Richard P Caplan highlights the fact that few studies have examined stress and psychological symptoms in senior doctors. ${ }^{1} \mathrm{We}$ conducted a cross sectional survey of 500 randomly selected NHS consultants in Scotland, of whom $375(75 \%)$ responded; this response rate compares well with the $77 \%$ response to the postal questionnaire that Caplan sent to consultants. We applied a wider range of questionnaires ${ }^{2}$ but report here our results with the general health questionnaire- 28 , in a manner comparable to Caplan's.

Of the 374 respondents whose responses to the general health questionnaire could be scored for caseness (for possible clinically important psychiatric distress), $80(21 \%)$ scored higher than 5 ; the mean (SD) score was $3 \cdot 0(4 \cdot 6)$. Eighteen consultants $(5 \%)$ had suicidal thoughts as derived from the severe depression section of the questionnaire. Our results show a prevalence of caseness roughly half that shown by Caplan. This difference could be partly explained by selection bias in Caplan's study since $17 \%$ of his respondents had

Score on general health questionnaire-28 and prevalence of suicidal thoughts by specialty

\begin{tabular}{|c|c|c|c|c|c|c|c|c|}
\hline & \multicolumn{8}{|c|}{ Medical specialty } \\
\hline & Medicine & Surgery & Anaesthetics & $\begin{array}{l}\text { Pathology/ } \\
\text { laboratory }\end{array}$ & $\begin{array}{l}\text { Obstetrics and } \\
\text { gynaecology }\end{array}$ & $\begin{array}{l}\text { Public } \\
\text { health }\end{array}$ & Psychiatry & Radiology \\
\hline \multicolumn{9}{|c|}{$\begin{array}{l}\text { General health questionnaire-28: } \\
\text { No }(\%) \text { with score }\end{array}$} \\
\hline $\begin{array}{l}>5 \\
\text { Median (range) }\end{array}$ & $12(15 \cdot 6)$ & $11(15 \cdot 3)$ & $14(34 \cdot 1)$ & $6(18 \cdot 2)$ & $10(27 \cdot 8)$ & $12(31 \cdot 6)$ & $9(23 \cdot 1)$ & $6(15 \cdot 8)$ \\
\hline $\begin{array}{l}\text { score } \\
\text { No (\%) with suicidal }\end{array}$ & $1(0-16)$ & $0(0-22)$ & $2(0-22)$ & $1(0-13)$ & $0(0-13)$ & $1(0-21)$ & $1(0-22)$ & $1(0-23)$ \\
\hline thoughts & $1(1 \cdot 3)$ & $2(2 \cdot 8)$ & $5(12 \cdot 2)$ & $2(6 \cdot 1)$ & $1(2 \cdot 8)$ & $2(5 \cdot 3)$ & $4(10 \cdot 3)$ & $1(2 \cdot 6)$ \\
\hline Total & 77 & 72 & 41 & 33 & 36 & 38 & 39 & 38 \\
\hline
\end{tabular}

effectively self selected themselves by accepting an invitation to attend a presentation by him on stress in the workplace. Our study was limited to consultants but permitted further analysis by specialty groups. The table shows differences in caseness and in the scores on the general health questionnaire (expressed as medians because of the skewed distribution) as well as the prevalence of suicidal thoughts. As in Caplan's categorisation for the same variables, the difference among the groups was not significant, although the highest rates seemed to be among anaesthetists.

As well as measuring outcomes we used qualitative and quantitative methods to derive a specialist doctors stress inventory to measure self reported stressors specific to health service consultants (R M Agius et al, unpublished findings). The score on this inventory showed highly significant correlations $(P<0.0005)$ with scores on the general health questionnaire $\left(r_{\mathrm{s}}=0 \cdot 26\right)$, and with suicidal thoughts $\left(r_{\mathrm{s}}=0 \cdot 18\right)$. Only part of the variance in psychological distress, however, was accounted for by work stressors, and underlying personality probably plays an important part. ${ }^{2}$ Further study is needed to elucidate the complex transaction between stress in the workplace, underlying personality, and adverse outcome in consultant doctors. Department of Psychology,

HARRIET BLENKIN London SE5 8AF

Postgraduate student

IAN DEARY Reader

Department of Psychology,

University of Edinburgh,

Edinburgh EH8 9JZ

ANDREW SADLER Research associate

Department of Public Health Sciences,

University of Edinburgh Medical School,

Edinburgh EH8 9AG

1 Caplan RP. Stress, anxiety, and depression in hospital consultants, general practitioners, and senior health service managers. $B M f 1994 ; 309: 1261-3$. (12 November.)

2 Deary IJ, Blenkin H, Agius RM, Endler NS, Zealley H, Wood RA. Models of job-related stress and personal achievement among consultant doctors. Br f Psychol (in press).

\section{Anomalous statistical notes}

EDITOR,-An interesting anomaly has arisen in the series of statistic notes. Seven articles have been published so far, on 11 June 1994, 9 July, 23 July, 24 September, 15 October, 29 October, and 21 January 1995. The first and second articles were numbered the first and second articles. The third article was numbered the eighth, the fourth was numbered the seventh, and the fifth was numbered the eighth again. The sixth and seventh articles were numbered the ninth and tenth respectively. There is a good correlation between the actual number of the article and the published number, though this does not reach significance $(P=0.06$, figure). It is difficult to be sure what the number of the next article is likely to be, although there is a $95 \%$ chance that it will lie between 8 and 16

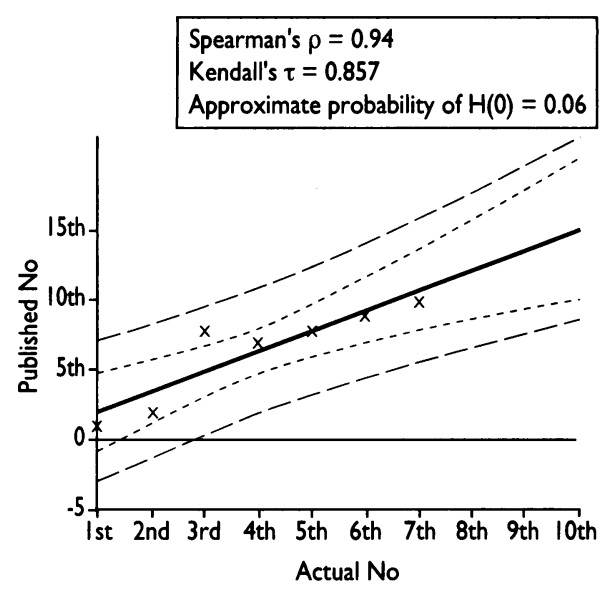

Predicted published number given to articles in series, with estimated 95\% confidence intervals for regression line (- . $--)$ and single points (_- - )

What really taxes me is where the third, fourth, fifth, and sixth articles have gone to. Maybe the answer is not significant anyway.

R S JAMES
General practice retainer

Stornoway,

Isle of Lewis,

Outer Hebrides PA86 0LQ

${ }_{*}^{*}$ Actually, we were not quite as bad as Dr James thinks. Because we published more notes than he counted (the extras were on 2 April, 4 June, and 1 July) we misnumbered only two (the fifth and the sixth, wrongly numbered the seventh and eighth). But we didn't want to spoil the joke. Sorry.EDITOR

\section{Correction}

\section{Severe chickenpox during treatment with} corticosteroids

Owing to a typesetting error the steroid dosage mentioned in the subheading of this letter by Isobel Burnett (4 February, p 327) is incorrect. The subheading should read: "Immunoglobulin should be given if steroid dosage was $\geqslant 0.5 \mathrm{mg} / \mathrm{kg} /$ day in preceding three months."

\section{Advice to authors}

We prefer short letters that relate to a recently published article and we are unlikely to publish letters longer than 400 words and containing over five references. Letters may be shortened. Your letters should be typed with double spacing and include a word count. All authors need to sign the letter and provide one current appointment and address. We encourage you to declare any conflict of interest. Please enclose a stamped addressed envelope if you require an acknowledgment. 